A rare resignation has focused attention on scientific societies' treatment of women. Theresa Markow, president of the Society for the Study of Evolution (SSE), has stepped down in protest that women were not adequately considered for the editorship of its journal, Evolution.

Many think the incident is symptomatic of a wider issue. "I see this as truly problematic," says Patricia Gowaty, an evolutionary biologist at the University of Georgia in Athens. "And it is not unique to the SSE"

The society's rules state that it should create a nominating committee to choose a chief editor. But instead, the society appointed a man after informal queries. It then rejected Markow's request to redo the process. Markow, a geneticist at the University of Arizona in Tucson, resigned the SSE presidency on 18 March, about ten weeks into her term.

${ }^{\alpha}$ I strongly feel that being inclusive with respect to gender ... is non-negotiable," Markow wrote in her resignation letter. ${ }^{\alpha} \mathrm{I}$ cannot serve as president of a society when the council and I share such major contrasts of view."

Officers at the SSE admit the selection process was flawed, adding that they regret Markow's departure. "This resignation has brought into focus the issue of participation of women," says ecologist Dolph Schluter of the University of British Columbia, Vancouver. “The society should address that." Schluter is the SSE's previous president, and he oversaw the search for an editor.

A committee has been formed to tackle the issue, Schluter points out. However, the society's 2,400 members were not informed of Markow's resignation until 11 April, after Nature called for comment.

In the SSE's nearly 60 years, Evolution has had only one female editor - Markow, from 1995 to 1999 . Other journals are similar. Daphne Fairbairn, an evolutionary biologist at the University of California, Riverside, says she had a "discouraging" experience when she proposed female candidates for an editing position at the Journal of Evolutionary Biology, published by the European Society for Evolutionary Biology. "No one else came up with a single woman candidate," says Fairbairn. "When I raised the issue, they looked at me dumbly."

She says society leaders criticized her suggestions unfairly. "They would say 'she is nasty', or 'she didn't do a good job'. No one was going through the men's list and saying those things." When Fairbairn's term as North American editor ends, the journal will have no female editors.

Juha Merila, a biologist at the University of Helsinki in Finland and the journal's editorin-chief, acknowledges there are difficulties appointing women. There are few women at high levels of science in Europe, he says, so the pool of candidates is small. "I am, of course, a little disappointed," he says. "I went through quite a few names; all declined because of other responsibilities."

The journal of the American Ornithologists' Union, The Auk, has not had a woman editor in its 123-year history. But Kimberley Sullivan, an ornithologist at Utah State University in Logan, has a grant from the US National Science Foundation (NSF) to address such issues, and seems to be making progress. The society's existing fellows pick new fellows at the union's annual meeting, from a slate of nominees. At her first fellows' meeting, Sullivan says women nominees were "trashed". "They started blackballing nominees, with someone saying: 'I was with her on a field trip and she misidentified a bird", she says. "It was terrible." The

\title{
Glint from tenth planet dazzles astronomers
}

When an object is 16 billion

kilometres away but probably only half the width of the United States, how do you work out precisely how big it is? That was the challenge faced by teams estimating the size of $\mathrm{UB}_{3 \mathrm{~B}}$, the potential 'tenth planet' in our Solar System, which was first spotted in 2003.

So far twoteams have tried, and come up with different answers.

The first group, led by Frank Bertoldi, an astronomer at the University of Bonn, Germany, measured how much heat $\mathrm{UB}_{313}$ emits, and compared it with the body's predicted temperature, based on its distance from the Sun. The team calculated that $\mathrm{UB}_{3 \mathrm{~B}}$ has a diameter of around 3,000 kilometres (F. Bertoldi et al. Nature 439, 563-564; 2006).

Now a team led by Michael

Brown, the planetary scientist at the

California Institute of Technology

whose group discovered $\mathrm{UB}_{313}$, has made its own estimate using the Hubble Space Teles cope. The researchers took 28 images of $\mathrm{UB}_{313}$ and inferred its size using its distance from Earth and the width of the object in the image - just 1.5 pixelsacross. They reckon it is around 2,400 kilometres in diameter, closer to the size of Pluto (see graphic).

That would make $\mathrm{UB}_{313}$ unusually bright for its size. Brown's team suggested on 11 April that the body reflects $86 \%$ of the light that falls

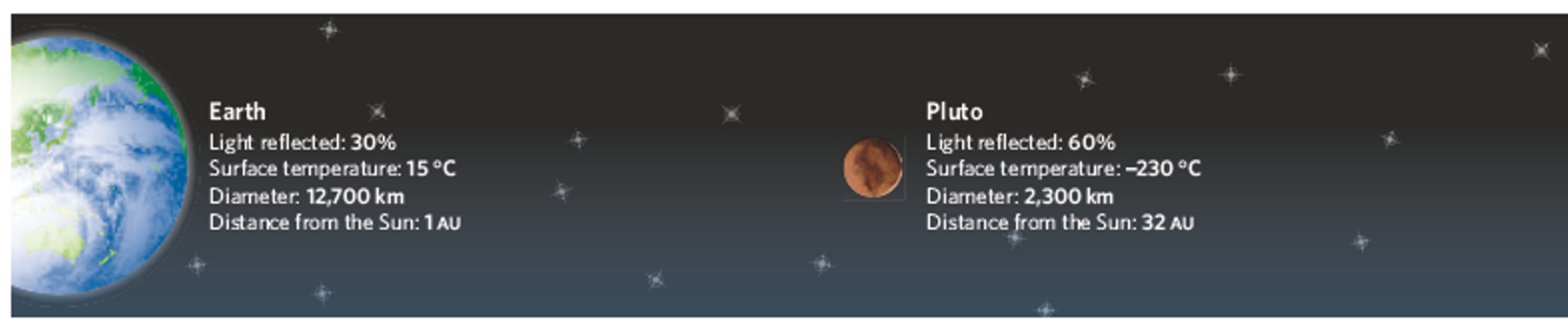




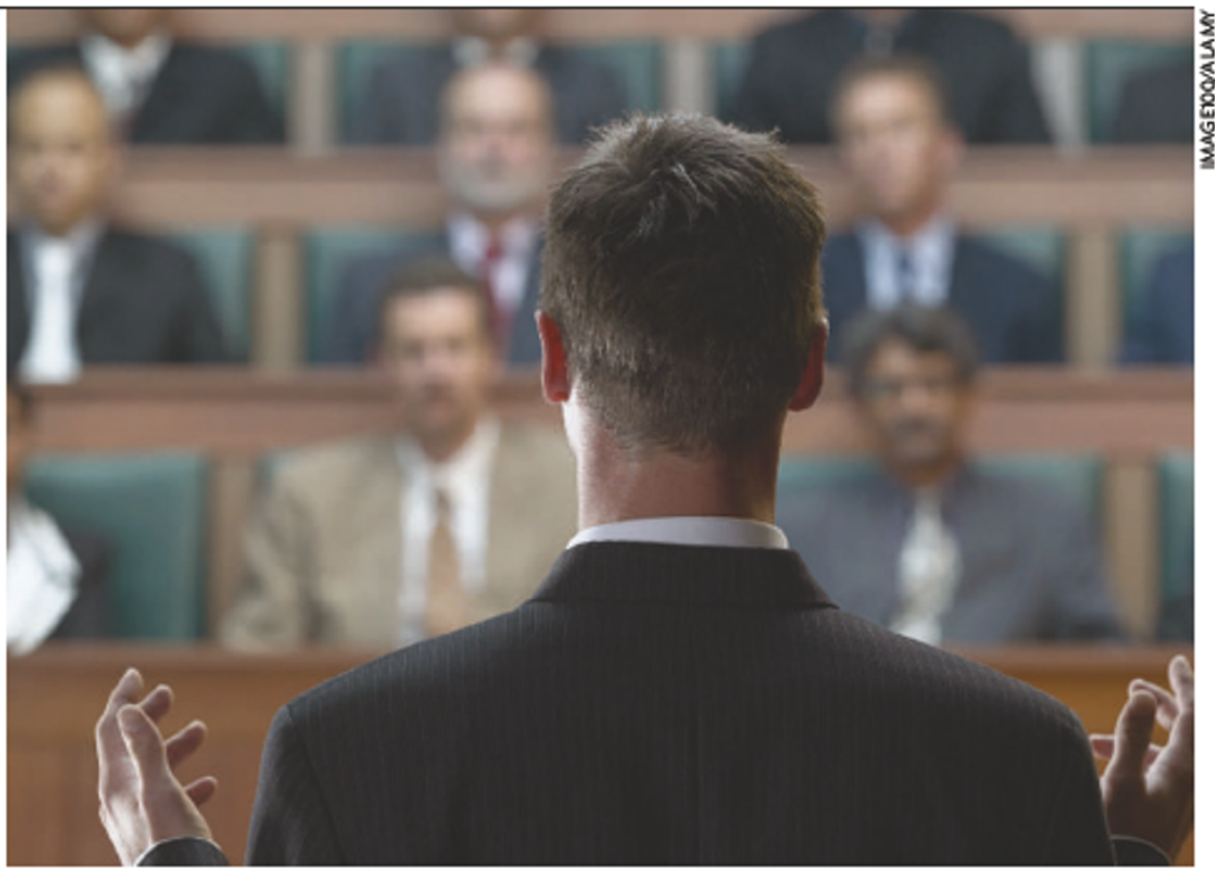

Aman's world? Women researchers accuse some societies of being old boys' clubs.

younger men on the slate came in for the same treatment, she says.

Sullivan presented data from her NSF study at last years' meeting, arguing that the union's tactics were turning it "from an old boys' club into an old men's society'. For the first time, the entire slate of prospective fellows was inducted without criticism. "I think the organization has been an old boys' club, says president-elect
Erica Dunn, of the Canadian Wildlife Service in Ottawa. "But the mood is to change."

For Robin Bell, a geophysicist at Columbia University in New York who has an NSF grant to promote women in Earth sciences, change can't come soon enough. "This is a civil rights issue," she says. "We are trying to create women leaders at the institutional level." RexDalton on it. The only object more reflective in the Solar System is Enceladus, a saturnian moon that gets its shiny surface from geysers, which spew water into the object's freezing atmosphere, creating ice on the surface.

Analys is of light reflected by $\mathrm{UB}_{313}$ shows that its high reflectivity is probably due to a coating of frozen methane. But that prompts questions about how the methane got there, and why cosmic rays, which splithydrogen atoms from methane molecules, have not added a layer of soot to the sur face. This process is thought to be responsible for red patches on Pluto's surface, which reflects a maximum of $60 \%$ of the light that falls on it.

"Why doesit have higher ice coverage than Pluto? We don't understandit well," says Bertoldi. The body may be leakingmethane from its warmer interior. Or it could be because $\mathrm{UB}_{313}$ used to be much closer to the Sun, so it may have had a methane atmosphere that froze to itssurface as itmoved farther out. The same fate probably awaits Pluto as its elliptical or bit takesit away from the Sun. Jim Giles
$2003 \mathrm{UB}_{313}$

Light reflected: $\mathbf{8 6 \%}$

Surface temperature: $-248{ }^{\circ} \mathrm{C}$

Diameter: $2,400 \mathrm{~km}$

Distance from the Sun: $97 \mathrm{AU}$
ON THE RECORD

"CESA is the only space agency to have science operations under way around four planets: Venus, the Moon, Mars and Saturn."

David Southwo od, director of the European Space Agency's science programmes, gets a bit confused about what constitutes a planet.

\section{cIt didn't come from a toilet on a plane or anything like that."}

Charles Glass of the Oakland Fire Department in Californiadiscusses a mysterious chunk of ice that fell from the sky and left a metre-sized crater in a city park. Meteorologists say that storms could not have made the ice.

Sources: ESA, Associated Press

\section{SCORECARD}

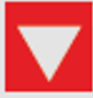

Freed am of speech

Mark Tushingham, a scientist at Environment

Canada, is ordered not to give a public talk abouthis futur istic novel Hotter Than Hell, in which droughts resulting from global warming cause Canada and the United States to go to war over water resources.

\section{$\nabla$} H5N1preparedness Asurvey of public-health workers in the United

States reveals that more than $40 \%$ say they wouldn't show up at work in the event of an influenza pandemic.

\section{NUMBER CRUNCH}

The potential effects on your health of eating chicken nuggets and fries vary depending on the country they're made in - an effect largely dictated by the cooking oil used, according to a recent survey.

$50 \%$ of food samples contained levels of trans fatty acids linked to an increased risk of heart disease.

$38 \%$ was the trans-fatty-acid content of KFC chicken nuggets bought in the Czech Republic, the highest in the survey.

$1 \%$ was the trans-fatty-acid content of similarnuggets bought in Spain.

Source: Stender, S, Dyerberg, 1 \& Astrup, A. N. Engl. J. Med. 354, 1650-1652 (2006) 